\title{
Las lágrimas: ese misterioso país
}

Lucrecia Maldonado*

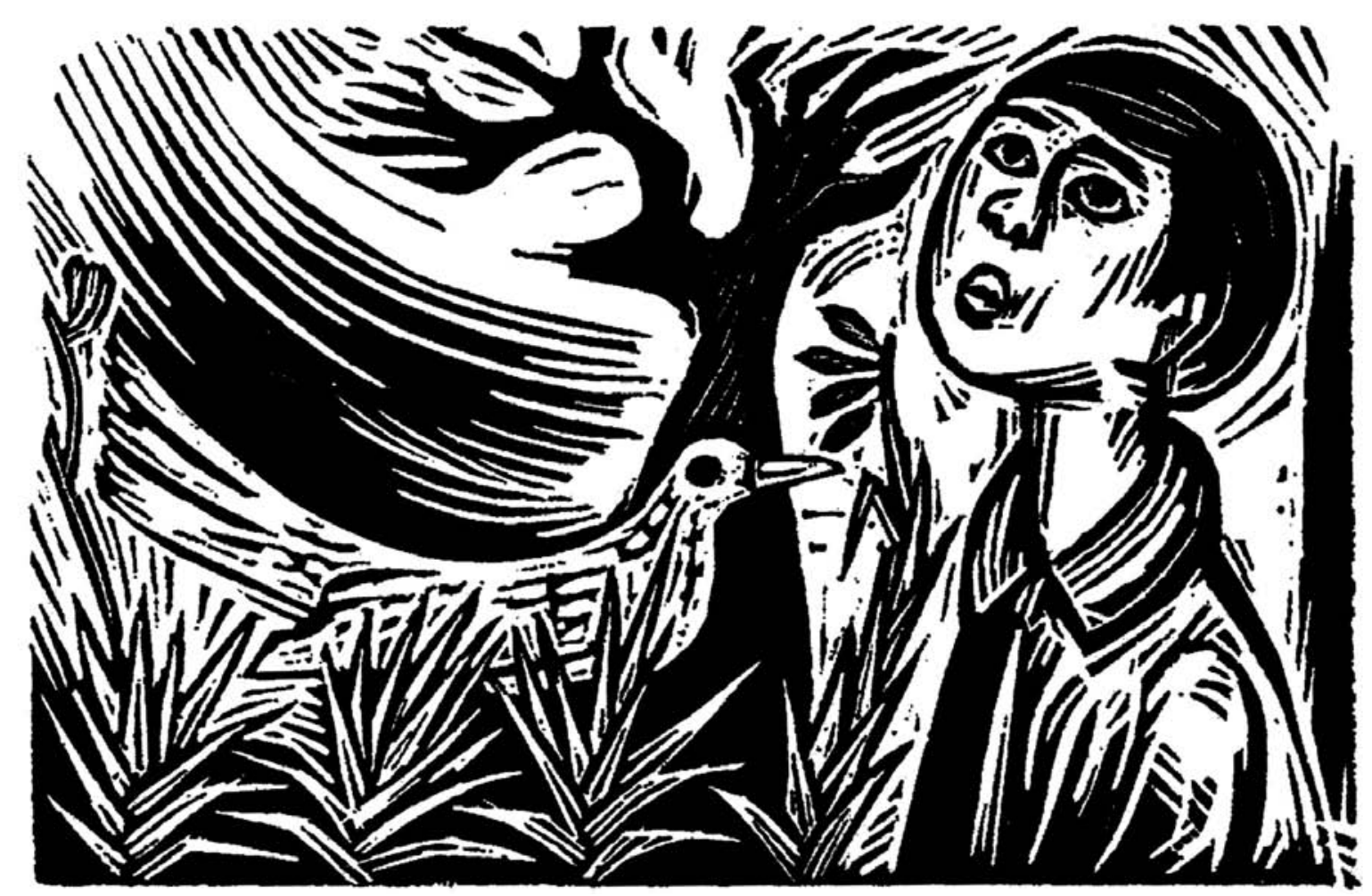

Niño y pájaro. 1948

¡Es tan misterioso el país de las lágrimas! [Antoine de Saint Exupéry]

Son las lágrimas jugo misterioso para calmar las penas de este mundo

[Luz Elisa Borja]

Pocas manifestaciones emocionales tienen tanta fuerza expresiva, motivadora y en ocasiones perturbadora como el llanto. Aunque es un comportamiento humano universal, y de seguro ninguna persona adulta puede negar que haya llorado unas cuantas veces por causas emocionales a lo largo de su vida, la mayor parte de gente tiene (tene- mos) una actitud ambivalente ante el hecho de llorar. Por un lado, se identifica la relación de las lágrimas con el alivio, aunque sea momentáneo, de los sentimientos que las provocan, sobre todo si es sufrimiento; por otro, el llanto se suele considerar algo que hay que contener, regular y disimular en un alto número de circunstancias.

Datos de la autora: Novelista y poeta. Ganadora del Premio Espinoza Pólit 2005 con la novela Salvo el Calvario (Planeta 2006). Alumna de la Maestría de Antropología y Cultura de la UPS. 
Por ejemplo, en una encuesta aplicada a treinta y dos personas de diferentes edades, aunque pertenecientes a un grupo social similar, la mayoría admite sentir alivio, desahogo, y algunos incluso una sensación agradable de relajamiento y sueño después de llorar; pero muchos de ellos prefieren llorar a solas o delante de personas de extrema confianza, y casi siempre se contienen y tienden a ocultar sus lágrimas en todo lo que sea posible.

Si bien los procesos del llanto se pueden explicar y comprender desde un punto de vista fisiológico y psicológico, existe una serie de variables que parecen tener estrecha relación con los sistemas de valores, la cultura y los condicionamientos impuestos por diversos grupos sociales en determinadas épocas de la historia.

\section{¿Cómo funciona?}

En el ángulo externo de cada ojo, debajo de los párpados superiores y detrás de las cejas, se encuentran las glándulas lacrimales, justamente ahí donde sentimos ese ardor, de intensidad variable, que se produce casi simultáneamente con el momento en que los ojos se van a llenar de lágrimas. Estas glándulas producen tres tipos de secreciones (Lutz, 2001: 77 y ss.):

- Lágrimas basales: permanecen en los ojos en forma de una fina película. Permiten el parpadeo, pues la córnea tiene una superficie llena de irregularidades que lo harían imposible si no fuera por el líquido que recubre y lubrica el globo ocular. Además, son antisépticas: contienen enzimas y sustancias que controlan la proliferación de gérmenes, e impiden la evaporación de la capa mucosa que recubre al ojo. Cuando la calidad o cantidad de las lágrimas basales se deteriora hablamos de la enfermedad conocida como el "ojo seco", muy molesta, y que incluso puede resultar peligrosa para la visión.

- Lágrimas reflejas: cuando hay un exceso de humo, de polvo, cuando un cuerpo extraño se introduce en los ojos o cuando algún producto químico irrita las mucosas (como es el caso de las emanaciones sulfurosas de la cebolla), las glándulas lacrimales secretan automáticamente lágrimas destinadas a expulsar las partículas extrañas o a defender y aliviar los ojos. Las lágrimas reflejas también se secretan cuando la función de las basales es deficiente. Por eso, en los casos de "ojo seco" los ojos más bien están húmedos, pues las lágrimas reflejas suplen la falta o mala calidad de las lágrimas basales.

- Lágrimas emocionales: ante una emoción intensa, de la clase que sea, o incluso ante un fuerte dolor físico, estas mismas glándulas secretan un tipo de lágrimas muy similares a las reflejas en tal cantidad que provocan una serie de 'trastornos' en ojos y nariz: taponan los conductos de drenaje lacrimal que se encuentran en la comisura interior del ojo, se acumulan entre los párpados y llegan a derramarse por sus bordes hacia fuera. Además invaden la nariz, enfriándola, lo que causa un incremento del riego de sangre en los capilares para evitar mayores variaciones en la temperatura del aire que ingresa por las fosas nasales, por esto se enrojece la nariz al llorar, y estos procesos de acumulación de sangre y líquido causan la irritación de los ojos y la conocida hinchazón de los párpados, todo proporcional a la cantidad de lágrimas y la duración del llanto y, desde luego, con grandes variaciones entre persona y persona.

\section{¿Por qué lloramos?}

Como el nombre indica, las lágrimas emocionales son aquellas que nacen de emociones intensas. Según el portal de Internet del Diccionario de la Real Academia de la Lengua Española (http://buscon.rae.es/draeI/), una emoción es una "Alteración del ánimo intensa y pasajera, agradable o penosa, que va acompañada de cierta conmoción somática”.

Según el psicólogo ítalo-argentino-colombiano Walter Riso, las emociones pueden catalo- 
garse como un "subproducto arcaico del cerebro” (Riso, 1997: 18) y como tales, están emparentadas con procesos muy antiguos de interacción con el medio y defensa de la propia integridad física. Riso habla de dos tipos de emociones:

- Primarias: "Las emociones primarias son aquellas con las que nacemos. Son naturales, no aprendidas, cumplen una función adaptativa, son de corta duración y se agotan a sí mismas" (Riso, 1997: 23). Las más importantes son el dolor, el miedo, la tristeza, la ira y la alegría, cada una con funciones particulares que facilitan la adaptación de la persona a cierto tipo de cambios y situaciones, así como su interacción con el medio.

- Secundarias: "son aprendidas, mentales, y aunque algunas de ellas, bien administradas, puedan llegar a ser útiles, no parecen cumplir una función biológica adaptativa. Son defensivas o manifestaciones de un problema no resuelto, y casi siempre implican debilitamiento del yo" (Riso: ídem). Dice Riso que estas emociones pueden considerarse prolongaciones mentales de las emociones primarias:

El dolor, la información corporal que nos permite saber cuándo un órgano anda mal, se extendió a supuestos "órganos mentales" y nació el sufrimiento. El miedo, el encargado de protegernos ante el peligro, se trasladó anticipatoriamente y creó la ansiedad. La tristeza, que permite desactivar el organismo para su posterior recuperación, se generalizó en un sentido autodestructivo en lo que se conoce como depresión psicológica. La ira, la principal fuerza interior para vencer obstáculos, se almacenó en forma de rencor y resentimiento. La alegría, la más poderosa e importante de las emociones, fue duramente restringida o convertida en apego al placer. (Riso, 1997: 24)

Las emociones, primarias y secundarias, provocan cambios en el organismo, sobre todo a nivel endocrinológico, y muchas veces los impulsos nerviosos ni siquiera llegan al cerebro, sino que parten de la médula espinal, es decir, son reflejos. Por ejemplo en el miedo, las glándulas suprarrenales secretan adrenalina, lo cual prepara el organismo para una posible huida, necesaria en caso de ser atacados por un enemigo poderoso. En la ira ocurre algo similar, pero la finalidad es atacar. El dolor físico (una de las principales causas de llanto entre los niños pequeños), el sufrimiento, la ira o frustración, y en ocasiones la alegría súbita e intensa pueden provocar llanto al

\section{Pocas manifestaciones emocionales tienen tanta fuerza expresiva, motiva- dora y en ocasiones perturbadora como el llanto. Aunque es un comportamien- to humano universal.}

estimular desde el sistema nervioso central las glándulas lacrimales.

Los análisis de laboratorio dan cuenta de una serie de sustancias presentes sólo en las lágrimas emocionales, como proteínas que el cuerpo genera ante situaciones de estrés o conmoción moral, lo cual haría pensar que son un vehículo para la excreción de sustancias producidas en ciertas situaciones que, de permanecer por mucho tiempo en el organismo, podrían resultar perjudiciales. Y de hecho se ha comprobado que la presencia de dichas sustancias puede provocar trastornos en la salud.

Pero ¿son las lágrimas solamente un mecanismo de depuración de un organismo que puede verse afectado por ciertas sustancias generadas por la conmoción y el estrés?

\section{Las lágrimas como lenguaje}

A diferencia de las basales e incluso de las reflejas, las lágrimas emocionales van acompañadas, para hablar en términos lingüísticos, por una serie de rasgos distintivos tales como expresiones sonoras (alteraciones en el timbre y tono de voz, suspi- 
ros, gemidos, sollozos...), y alteraciones en la fisonomía (los "pucheros", el cambio de ángulo de inclinación de las cejas...), que Charles Darwin se encargó de observar y catalogar detenidamente en su estudio La expresión de las emociones en el hombre y los animales (citado frecuentemente en Lutz, 2001). Darwin descubrió y clasificó más de cien gestos característicos diferentes que se presentan en el llanto, y afirma que es una de las "expresiones específicas del hombre" (Lutz, 2001: 14), pues ninguna otra especie ha dado pruebas de poseer los mecanismos de las lágrimas emocionales. En un plano más filosófico y un tanto humorístico, don Miguel de Unamuno afirma:

El hombre, dicen, es un animal racional, no sé por qué no se haya dicho que es un animal afectivo o sentimental [...] Más veces he visto razonar a un gato que no reír o llorar. Acaso llore o ría por dentro, pero por dentro acaso también el cangrejo resuelva ecuaciones de segundo grado. (Miguel de Unamuno, 1962: 6-7).

Las lágrimas emocionales también dejan una visible huella en el rostro de quien ha llorado. De igual manera, estas señales suelen funcionar como una evidencia y muchas veces son las que dan cuenta de la intensidad y duración del llanto, incluso cuando la persona se ha preocupado de disimularlo.

Por estas características se podría decir que el llanto, a más de ser un proceso fisiológico de depuración orgánica ante las emociones intensas, es también un medio de comunicación. Según Jeffrey A. Kottler, "los lingüistas culturales describen el llanto como un tipo de paralenguaje que, deliberada o inconscientemente, sirve de soporte a la expresión emocional verbal" (Kottler, 1997: 39).

$\mathrm{Si}$ atendemos a las respuestas de nuestra encuesta, solamente dos personas $(6,2 \%)$ les reconocen a las lágrimas su real función excretora de eliminar sustancias producidas por el estrés. Para la mayoría, el llanto sirve tanto para desahogar los sentimientos (28 respuestas, el 87,5\%) como para comunicarlos (15 respuestas, $46,9 \%$ ).

De hecho, las lágrimas tienen una estrecha relación con el lenguaje, ya sea como un recurso

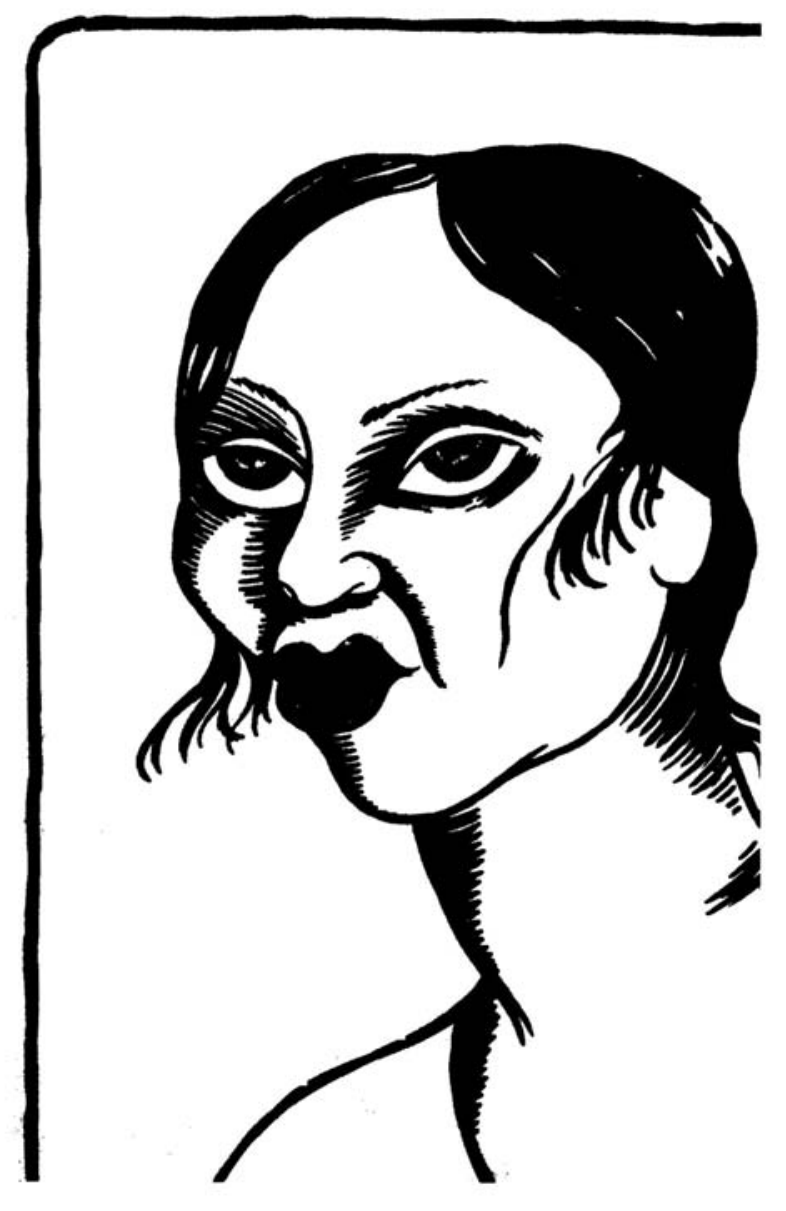

Señora. 1940

literario o como un elemento que se prefiere suprimir. En conversaciones es frecuente escuchar frases como "llorar como un niño", "estar hecha una Magdalena", "pórtese como hombre". Este tipo de expresiones representan creencias comunes relacionadas con el llanto: los niños lloran con menos inhibición y control que nadie; las mujeres lloran mucho, siguiendo el ejemplo de un conocido personaje bíblico; un hombre que llora no se porta como tal...

Y si atendemos a la literatura y el arte, las lágrimas se utilizan como un importante recurso para mostrar no sólo la existencia de las emociones, sino también su autenticidad, $y$, a partir de ello, provocar reacciones en quienes observan esta manifestación, como lo demuestra este conocido soneto de Sor Juana Inés de la Cruz: 


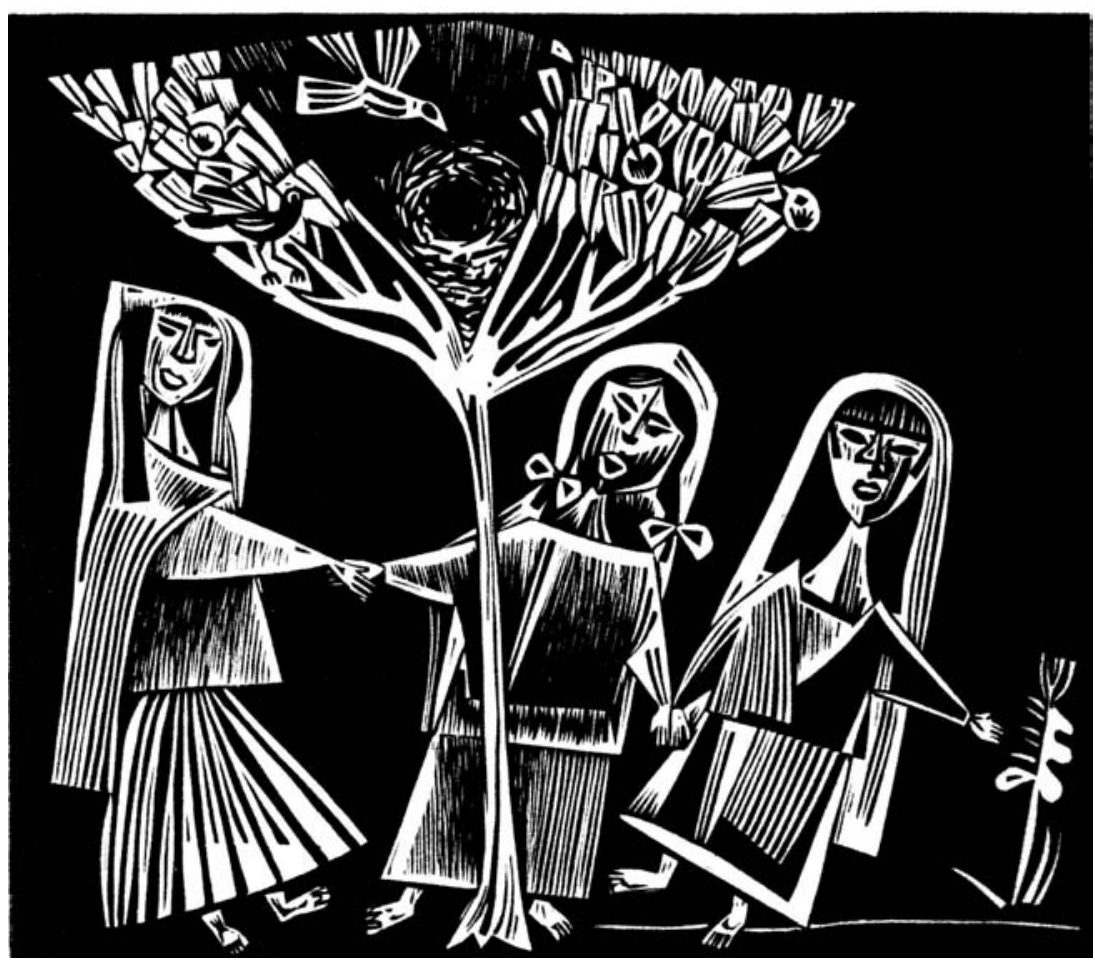

La pájara pinta, 1952. Serie Juegos infantiles por estar mucho tiempo en la misma postura. Un niño menor de diez meses llora por algo muy concreto: una necesidad puntual que las madres tratamos de satisfacer lo más pronto posible, y no sólo por amor materno, sino porque el llanto de un bebé tiene frecuencias sonoras tan agudas y estridentes que en ocasiones puede volverse exasperante. De ahí que sea tan difícil cumplir el famoso "déjenle llorar" de las abuelitas, o que el llanto de algunos infantes provoque reacciones violentas en padres y madres irritables.

A eso de los nueve o diez meses de vida, los bebés comienzan a advertir que los adultos se esfuerzan -normalmentepor consolar su llanto, y comienzan a utilizarlo como reclamo para situaciones menos apremiantes que las de la primera etapa. Mucho depende de la reacción de los padres el uso que estos niños darán después a sus lágrimas, pues es sabido que, así como hay padres que suelen ignorar el llanto de sus hijos, otros en cambio se desviven por contentarlos, entonces los niños convierten al llanto en una de sus mejores armas persuasivas y de presión a lo largo de su infancia e incluso más tarde.

En la encuesta realizada para este artículo, el

Baste ya de rigores, mi bien, baste: no te atormenten más celos tiranos, ni el vil recelo tu inquietud contraste

con sombras necias, con indicios vanos, pues ya en líquido humor viste y tocaste mi corazón deshecho entre tus manos. (Tomado de http://members.tripod.com /Heron5/sor1.htm, los resaltados son míos)

Si son un lenguaje, ¿qué dicen las lágrimas? En etapas tempranas de la vida hablan de necesidades muy básicas: hambre, dolor físico, fatiga dolor y la tristeza se siguen considerando la mayor causa de llanto, reconocida así por 26 $(81,25 \%)$ de los 32 encuestados, causa que es seguida por la ira, con $12(37 \%)$ respuestas, 8 de las cuales son respuestas femeninas. El resto de motivos, incluso la alegría, les siguen muy de lejos. Y esto se puede aplicar a la mayoría de casos y personas. El llanto por dolor físico, salvo que sea un dolor extremo, en todas las culturas se termina en la pubertad o antes, aunque en esta situación se vuelve más patente el alivio que provocan las lágrimas, aunque sea momentáneo. 
Pero, aunque no con tanta frecuencia, también lloramos de alivio emocional cuando una situación de angustia o estrés se resuelve favorablemente. Es común hablar del llanto de alegría, con diversos matices: gratitud por gestos de afecto o de reconocimiento, reencuentros después de largas separaciones, reconciliaciones, logros esperados o inesperados, los típicos llantos de las Misses, de los ganadores de todo tipo de premios, o los nada sorpresivos llantos de los deportistas y sus hinchas cuando se gana.

A veces el llanto de la alegría lleva un matiz nostálgico: la gratitud cuando recibimos algo que no creíamos merecer, o ante momentos felices de cuya fugacidad estamos más conscientes de lo que quisiéramos. Los logros y avances de nuestros hijos, que van marcando su crecimiento y la distancia emocional que implica (existen madres que lloran en todos los eventos escolares de sus niños, sean estos la fiesta de Navidad, la entrega de libretas o cualquier otro tipo de ceremonia), las celebraciones, que, a la par que nos convocan, marcan el paso del tiempo y la brevedad de los encuentros...

Una importante causa de llanto es también la empatía, entendida como la "identificación mental y afectiva de un sujeto con el estado de ánimo de otro" (http://buscon.rae.es/draeI/). Una joven confiesa que llora siempre que ve llorar a alguien más, sea por lo que sea, y esta identificación se vuelve casi total si ve llorar a un hombre. En este mismo sentido se llora, y mucho, al ver el sufrimiento o la emoción de los personajes de las películas y de las seriales de televisión.

Un estudio del llanto en los cuentos de Julio Cortázar cita a Alfred Stern en su Filosofía de la risa y el llanto, y señala las siguientes categorías para encontrar la causa de las lágrimas:

- las lágrimas de angustia, de miedo, de inquietud que expresan valores amenazados por el mundo intruso;

- las lágrimas del deseo insatisfecho que expresan valores irrealizados o irrealizables;

- lágrimas de la desesperación que expresan valores irrealizables;
- lágrimas de tristeza, de duelo que expresan valores perdidos. ${ }^{1}$

Según Stern, entonces, el llanto proviene de una valoración de un objeto, de un deseo, de un anhelo o de una relación que se ha perdido (lágrimas de duelo y tristeza), que tememos perder (lágrimas de angustia y miedo), que sabemos imposible de alcanzar (lágrimas de desesperanza y deseo insatisfecho) o, me atrevería a agregar, que sorpresivamente alcanzamos, en la realidad o la imaginación (lágrimas de alegría o de emoción).

\section{El miedo a las lágrimas}

Existen en el lenguaje una serie de eufemismos para mencionar el llanto o las lágrimas: "me puse mal", a fulanito se "le fueron las lágrimas", "fue un momento muy emotivo", "no quiero ponerme mal ahora"... por no decir: lloré, fulanito lloró (eso de írsele las lágrimas a alguien coloca al llanto en una posición de acto completamente reflejo e involuntario, quitando 'responsabilidad' sobre él a la persona que llora), fue un momento en el que todos lloraron, ahora no quiero llorar... O sea, el verbo llorar, así, al desnudo, pertenece a ese grupo de palabras que la gente, por alguna razón no muy clara, prefiere evitar siempre que le sea posible.

Aunque todas las virtudes de las lágrimas emocionales son reconocidas y valoradas en el discurso, es frecuente tratar de impedir o por lo menos abreviar el llanto de los demás así como el propio, sobre todo si estamos en público. La mayoría de ocasiones, en cuanto se advierte que alguien comienza a ceder ante el impulso de sus lágrimas, los esfuerzos se dirigen a impedir este desahogo, aunque sea veladamente ("tranquilo, tranquilo...”), pues las lágrimas ajenas provocan, sobre todo empatía y en muchos casos pena por quien llora, lo cual puede implicar también un "contagio" que casi siempre tratamos de evitar.

Las lágrimas emocionales son más susceptibles de ser controladas y contenidas que, por ejemplo, las reflejas. Y la mayoría de personas da 
una cierta batalla a sus lágrimas, por lo menos mientras le resulta posible. Así mismo, mucha gente prefiere llorar en ámbitos privados, o cuando mucho rodeados de personas pertenecientes a un círculo íntimo.

De igual manera, si el llanto nos ha dejado huella en el rostro, preferimos que solamente nos vean personas cercanas o de confianza. Y casi siempre intentamos disimular lavándonos la cara o, en el caso de algunas mujeres, con algo de maquillaje. Pero ni el agua ni el maquillaje sirven más que para autoengañarnos y evidenciar más aún la vulnerabilidad y el temor ante las propias lágrimas.

¿Por qué las contenemos y las ocultamos? Es posible que en estos tiempos de proactividad, sentido práctico y culto al éxito, las lágrimas hayan sido desvalorizadas en tanto en cuanto pueden interpretarse como fragilidad, agotamiento emocional o fracaso. Pero no siempre fue así.

\section{"Los hombres no lloran"}

Cuenta una leyenda que cuando el rey Boabdil el Chico abandonaba la ciudad de Granada tras su derrota ante los reyes católicos, al mirarla desde las montañas, rompió a llorar. Su madre, que iba con él, le dijo, indignada: "Llora como mujer lo que no supiste defender como hombre". Esto, que suena muy lógico de acuerdo a los parámetros que manejamos en la actualidad, es muy poco probable que haya sucedido tal cual en la época a la que correspondería el relato: el final de la Edad Media. Según otros relatos de la misma época u otras cercanas, en aquel entonces, más bien la norma era que hombres y mujeres fuesen muy expresivos:

La épica heroica, desde los griegos hasta la Edad Media, está bañada de toda suerte de lágrimas. En el poema épico del siglo VIII, Beowulf, Hrothgar, rey de los daneses, agradece a Beowulf por ayudar a restablecer la paz dándole doce joyas, luego de lo cual "asió al héroe por el cuello y lo besó mientras las lágrimas manaban de su cabeza gris". Roland, uno de los guerreros de Carlo- magno inmortalizado en el Cantar de Roland del siglo XII, llora libremente e incluso le es permitido desmayarse. Cuando Oliver, el amigo de Roland, muere en batalla, "Roland llora lamentándose amargamente;/ Muchos han penado, pero ninguno como él", y entonces se desmaya en la silla de montar. Cuando Roland mismo muere, Carlomagno "se jala las barbas de angustia y dolor./ Los señores de Francia lloran amargas lágrimas, /Y veinte mil se desmayan de pena y caen [...] No hay uno solo entre estos nobles señores/ Que pueda contenerse y no derrame lágrimas de pena”. (Lutz, 2001: 70-71)

En estos relatos, sobre todo en lo que al desmayo de veinte mil hombres se refiere, es posible que haya una intención hiperbólica; pero de todas formas se reconoce y acepta la normalidad de un llanto masculino intenso y prolongado. Como se verá, los textos épicos citados no hablan de clérigos, hombres de grandes experiencias espirituales ni artistas, sino de guerreros que, así como podían llorar hasta desmayarse, también eran fieros y aguerridos en las batallas. $\mathrm{Al}$ igual que Carlomagno, Roland o Hrothgar, otros héroes tienen importantes momentos de llanto en la literatura épica. Recordemos a Aquiles y a Odiseo, protagonistas de la Ilíada y la Odisea, y respectivamente guerrero más bravo y estratega de la guerra de Troya, quienes ante el dolor, la alegría de los reencuentros e incluso la cólera no tienen ningún empacho en derramar lágrimas, con frecuencia acompañadas de un gran despliegue dramático. Y jamás se llega a insinuar siquiera que esto pudiera ir en desmedro de su valentía o su virilidad.

De igual manera, en la Edad Media el llanto se suele relacionar con experiencias espirituales de hombres y mujeres santos. De San Francisco de Asís, por ejemplo, existen no solamente abundantes relatos en los que el santo llora por pura emoción mística, sino que la creencia popular afirma que al final de su vida se quedó ciego de tanto llorar.

Sin embargo, los relatos de Aquiles, Odiseo, Beowulf, Roland, o las historias sobre San Fran- 
cisco de Asís y otros santos y santas del pasado pertenecen a una época en donde las emociones expresadas traducen fuertes sentimientos de amistad y filiación, así como una gran espiritualidad, valores muy representativos en aquellos tiempos.

Incluso en el Romanticismo encontramos poemas como esta rima de Bécquer, cuya última estrofa da cuenta de la fortuna de 'tener lágrimas':

Triste cosa es el sueño que llanto nos arranca, mas tengo en mi tristeza una alegría... ¡Sé que aún me quedan lágrimas!

(Bécquer, 2002: 194, el resaltado es mío)

Y los personajes románticos, reales o de ficción, son en general muy propensos al llanto. Sin embargo, el mismo Bécquer ya habla en su poesía de una cierta diferenciación entre el llanto de la mujer y el hombre al decir:

\section{¡Llora! No te avergüences}

de confesar que me quisiste un poco.

¡Llora! Nadie nos mira.

Ya ves; yo soy un hombre...,

¡y también lloro!

(Bécquer, 1968: 29, el resaltado es mío)

En la palabra también se evidencia la creencia o idea de que los hombres no lloran tanto, no lloran del mismo modo que las mujeres, o algo aún peor: al llorar se humillan o se degradan, pero igual lo hacen.

El llanto comienza a considerarse como una actitud vergonzante, sobre todo para los hombres, más o menos desde mediados el siglo XVIII, cuando a partir de la Ilustración, se le da a la razón, o al razonamiento lógico, una preeminencia sobre lo intuitivo o lo sentimental. En el Romanticismo se revaloriza la sensibilidad humana y sus manifestaciones; pero más tarde, en la segunda mitad del mismo siglo XIX, el Positivismo y la Revolución Industrial, sobre todo esta última, pondrán en entredicho el llanto no solamente masculino, pero sí el masculino por enci-
Se puede pensar que un hombre que llora en momentos de crisis no está cumpliendo a cabalidad con sus funciones de proveedor y sobre todo de protector y coordinador del núcleo familiar. Sus lágrimas, a más de considerarse inútiles, pueden ser interpretadas como una actitud de huida.

ma de todo, pues quien llora no está razonando ni produciendo bienes tangibles, sino que más bien coarta o impide la producción, y atenta contra la productividad como concepto o valor.

Sin embargo, en la literatura de la época las lágrimas siguen teniendo una presencia importante, que de seguro no se correspondía con la realidad. Recordemos si no el melodramatismo realista de las novelas de Dickens, o de obras como Los hermanos Karamazov de Fyodor Dostoyevski, en donde Alioscha, por ejemplo, da rienda suelta a su dolor por la muerte del abate del monasterio con una efusión de lágrimas y sollozos narrada con detalle por el genial escritor.

Se puede pensar que un hombre que llora en momentos de crisis no está cumpliendo a cabalidad con sus funciones de proveedor y sobre todo de protector y coordinador del núcleo familiar. Sus lágrimas, a más de considerarse inútiles, pueden ser interpretadas como una actitud de huida, o como un estorbo cuando hace falta que alguien actúe. Pero es frecuente que, en estos casos, los hombres que contienen su llanto tengan actitudes violentas como gritos $\mathrm{u}$ otro tipo de agresiones contra objetos o personas, lo cual, si nos ponemos a ver, también resulta inútil, intimidante y agotador.

En los años finales del siglo XX y en los de inicio del siglo XXI las actitudes represivas ante el llanto masculino se han relajado un poco. Y, según Jeffrey A. Kottler, quizá se lo debamos al feminismo:

El impacto del feminismo, el movimiento de los hombres, la igualdad de los géneros y los valores 
de androginia facilitarán a los hombres el llorar más abiertamente. Este es especialmente el caso en que los hombres expresan lágrimas que tienen origen en las maneras distintivamente masculinas de relacionarse con los demás como padres e hijos, como hermanos y amantes, como amigos y guerreros. (Kottler, 1997: 183).

Esta nueva actitud se manifiesta en las respuestas a nuestro modesto sondeo, en donde 26 personas $(81,25 \%)$ responden que la frase "los hombres no lloran" es totalmente falsa, nadie responde que sea totalmente cierta, y las seis personas que la reconocen como cierta en algunas circunstancias, atribuyen este hecho, sobre todo a los modelos y condicionamientos sociales antes que a una dificultad esencial o fisiológica del hombre para llorar.

Por otro lado, las causas de llanto masculino sí se diferencian un poco de las del femenino: lloran menos de ira, la desfogan con actitudes más violentas, y sólo cuando algo les impide este último desahogo pueden terminar expresando su furia en lágrimas. En cuanto al dolor o sufrimiento, incluso cuando la prohibición social era más estricta, pocos hombres lograban contenerse en circunstancias de duelo familiar.

Un estudio realizado por William Lombardo desveló que la probabilidad de que los hombres lloren en respuesta a situaciones en que también llorarían las mujeres se limita a dos casos: la muerte de un ser querido y una experiencia religiosa conmovedora (Kottler, 1997: 167).

Asimismo, es muy frecuente que los hombres repriman el llanto, pero de una manera en la cual se note que lo están haciendo, lo que puede volver más conmovedor el notorio esfuerzo por mantener lo que se podría catalogar como "fortaleza”. En lo que a forma se refiere, los llantos masculinos pueden ser radicalmente diferentes a los llantos femeninos: "Para los hombres que admiten el llanto, sólo el 15\% solloza y se sacude cuando lloran, en comparación con el $65 \%$ de las mujeres. La gran mayoría de las veces (61\%), para los hombres el llanto significa tener los ojos rojos y verter una o dos lágrimas" (Kottler, 1997: 167)
Sea como sea, el mismo Jeffrey Kottler afirma: "Casi todos los hombres tienen dentro de sí la capacidad para hablar profundamente a través de las lágrimas; sólo hay que saber escucharlas" (Kottler, 1997: 164).

\section{¿Quien llora 'siente' de verdad?}

O eso parecería, pues las lágrimas son un proceso que en la mayoría de los casos se considera imposible o por lo menos muy difícil de falsificar. Esta es la creencia al uso, demostrada además porque el llanto es algo que más bien tratamos de ocultar, casi siempre con resultados entre lo malo y lo peor, pues por si no fuera poco con el hecho mismo de casi siempre terminar llorando a pesar de todos nuestros esfuerzos, deja en la cara esas traicioneras y perturbadoras marcas que bastan para delatar nuestra fragilidad.

Pero a veces las emociones que provocan lágrimas pueden nacer de situaciones artificiales o de las características especiales de ciertos momentos. Observemos esta cita de Borges, tomada de su cuento "El espantoso redentor Lazarus Morell":

"Yo lo vi a Lazarus Morell en el púlpito, anota el dueño de una casa de juego en Baton Rouge, Luisiana, y escuché sus palabras edificantes y vi las lágrimas acudir a sus ojos. Yo sabía que era un adúltero, un ladrón de negros y un asesino en la faz del Señor, pero también mis ojos lloraron" (Borges, 1983: 11, el resaltado es mío)

La frase es muy gráfica: "sabía que era un adúltero, un ladrón de negros y un asesino en la faz del Señor, pero también mis ojos lloraron". Sabiamente, el autor no pone en la voz del personaje las palabras "pero también yo lloré", sino que le hace tomar una distancia del hecho: "también mis ojos lloraron", como si los ojos tuvieran una vida independiente, más allá de la vida racional (saber, conocer todas las detestables características de Lazarus Morell) y emotiva del personaje.

Muchas personas, sobre todo mujeres, confiesan con frecuencia que el solo hecho de ver llo- 
rar a alguien más, aunque no sepan exactamente el motivo de ese llanto, ya les provoca lágrimas.

Por otro lado, si volvemos al soneto de Sor Juana Inés de la Cruz, notaremos que, envuelta en bellas palabras, se esconde una intención, si no manipuladora, por lo menos de intención hondamente persuasiva en el hecho de llorar:

Baste ya de rigores, mi bien, baste: no te atormenten más celos tiranos, ni el vil recelo tu inquietud contraste

con sombras necias, con indicios vanos, pues ya en líquido humor viste y tocaste mi corazón deshecho entre tus manos.

Un relato de Julio Cortázar, "Conducta en los velorios", evidencia con gran agudeza la preeminencia de las funciones comunicativas y sociales del llanto por encima de sus funciones fisiológicas y psicológicas:

No vamos por el anís, ni porque hay que ir. Ya se habrá sospechado: vamos porque no podemos soportar las formas más solapadas de la hipocresía. Mi prima segunda, la mayor, se encarga de cerciorarse de la índole del duelo, y si es verdad, si se llora porque llorar es lo único que les queda a esos hombres y a esas mujeres entre el olor a nardos y el café, entonces nos quedamos en casa y los acompañamos desde lejos. A lo sumo mi madre va un rato y saluda en nombre de la familia, no nos gusta interponer insolentemente nuestra vida ajena a ese diálogo con la sombra. Pero si de la pausada investigación de mi prima surge la sospecha de que en un patio cubierto o en la sala se han armado los trípodes del camelo, entonces la familia se pone sus mejores trajes, espera a que el velorio esté a punto, y se va presentando de a poco pero implacablemente (Cortázar, 1991: 52).

Este es el párrafo inicial de un hilarante cuento sobre una familia que tiene la costumbre de desestabilizar los funerales del barrio entrando en reñidas competencias de llanto con los deudos, quienes, a todas luces, lloran con la intención de avalar una aflicción que, más allá

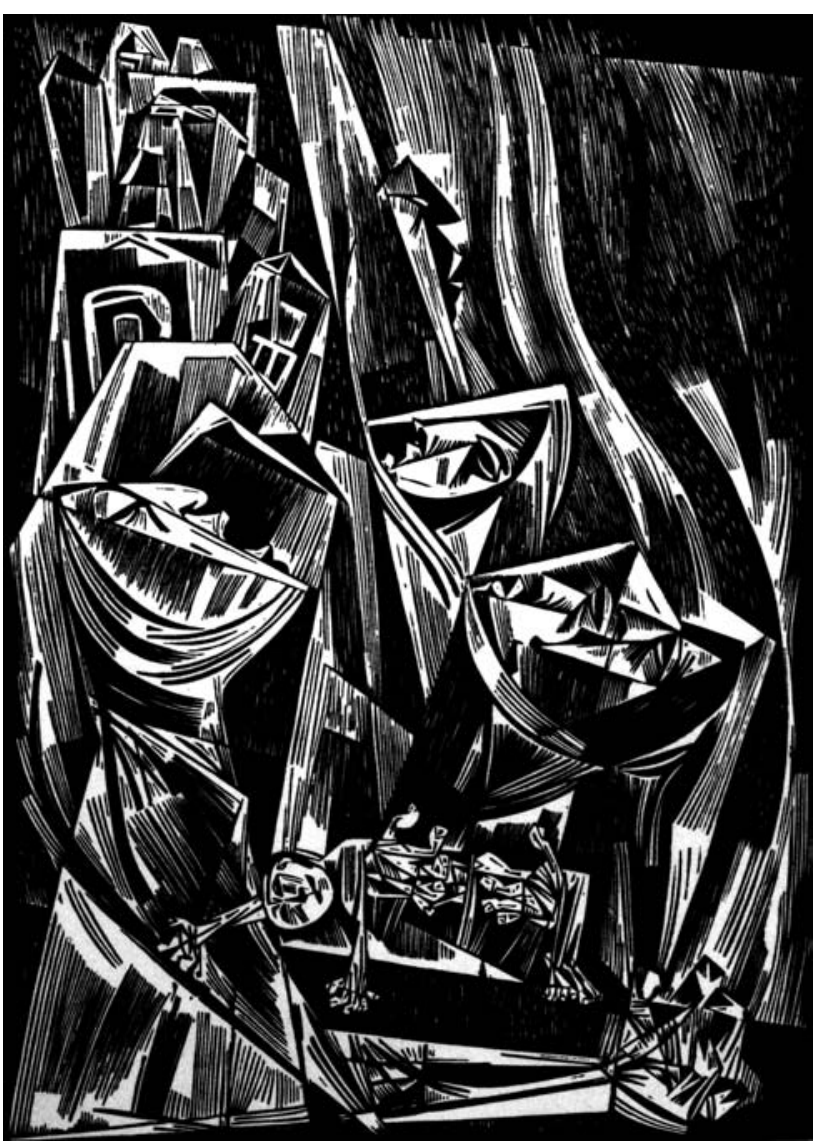

Desolación y muierte, 1953. Serie Bomba atómica

de reflejar sentimientos auténticos, cumple con una expectativa social: "Llegamos de a uno o de a dos, saludamos a los deudos, a quienes se reconoce fácilmente porque lloran apenas ven entrar a alguien..." (Cortázar, 1991: 53). El relato está lleno de incidentes propios de una comedia del cine neorrealista italiano, donde la familia se esfuerza por demostrar que ellos sienten la pena más que los vecinos, y los "rompe funerales" hacen de las suyas a punte lágrimas para sacar a la luz la falta de sinceridad del llanto de la parentela: "mis tres primas segundas se largan a llorar sin afectación, sin gritos, pero tan conmovedoramente que los parientes y vecinos sienten la emulación, comprenden que no es posible quedarse así descansando mientras extraños de la otra cuadra se afligen de tal manera" (Cortázar, 1991: 54). 
Esto, que en el cuento de Cortázar provoca risa y reboza cinismo, no lo hace tanto así en la vida real. Al morir la madre, muy anciana, de una amiga, con una muerte rápida e indolora, la admiración de las hermanas porque mi amiga no hubiera llorado en el funeral, porque tuviera fuerzas y entereza para decir unas palabras de despedida e incluso acompañar con su canto en la misa de honras, se parecía demasiado al reproche.

Es paradójico, sin embargo, a pesar de la valoración de las lágrimas como manifestación de aprecio, respeto, cariño y dolor por quien ha muerto, el hecho de que muchas personas, sobre

\section{Las lágrimas tienen una función so-} cializadora, no solamente comunicativa, sino también integradora de las personas que experimentan emociones iguales o similares.

todo en determinados grupos sociales, se inhiban de llorar en los funerales y guarden sus lágrimas de duelo para momentos más 'privados', y que otros lleguen al extremo de tomar tranquilizantes para inhibir lo que se podría considerar un llanto exagerado en las ceremonias fúnebres. El ser humano en duelo parecería encontrarse en una confusión: por un lado, necesita manifestar sentimientos de aprecio por un difunto y dolor por su partida; por otro desea demostrar control sobre las manifestaciones emocionales, y más que ninguna, sobre el llanto, que de alguna manera se considera vergonzante quizá porque se relaciona con la fragilidad humana, tan patente en el momento de la muerte.

\section{Lágrimas rituales}

Existen dos ámbitos bien diferenciados en donde las personas solemos dar rienda suelta al llanto: uno, el privado, que puede incluir la soledad y el ocultamiento total (encerrarse en un baño, un dormitorio, buscar el tiempo que precede al sueño...) o la presencia de personas muy íntimas o cercanas; el otro, el público, en el que pueden incluirse sitios como los cines, estadios, teatros... o también el ámbito de las ceremonias que marcan transiciones importantes en la vida de las personas, las familias y las comunidades.

Según el estudio de Tom Lutz, una de las funciones del llanto es la de obligar a la persona a atender a una compleja serie de sensaciones que la distraen de la intensidad de las emociones que experimenta. Alguien que llora debe, por fuerza y aunque sea colateralmente, volver su atención hacia las secreciones que manan de sus ojos y nariz y hacia las sensaciones corporales que las acompañan. La misma actitud que algunas personas toman al llorar demuestra una necesidad de separación o distanciamiento del mundo: ocultar la cara entre las manos, cubrir los ojos o toda la cara con un pañuelo, cubrirse la boca para sofocar sollozos... no son tanto acciones profilácticas, de higiene o de decoro, cuanto evidencias de que se pretende ocultar, de una parte, el rostro que llora al mundo, y de otra (quizá la más importante) ocultar a nuestra visión un mundo que nos resulta doloroso, angustiante o quizá demasiado maravilloso como para poder creérnoslo.

Muchas personas piensan que cuando lloran delante de otros, sobre todo en situaciones difíciles, restan coraje a los demás. Un estudiante de último año de secundaria confiesa que, pese a su enorme pena, había evitado llorar en todo lo que le fue posible cuando murió su abuela porque "si mi mamá me veía llorar, se iba a poner peor”, es decir, era una manera, bastante ingenua por cierto, de proteger a su madre del dolor por la pérdida de la abuela.

Pero las lágrimas tienen, como vimos, una función socializadora, no solamente comunicativa, sino también integradora de las personas que experimentan emociones iguales o similares. De ahí que con frecuencia sea un abrazo el detonante del llanto de quienes se abrazan, o el modo más íntimo y cercano de compartir lágrimas provocadas por una emoción compartida. 
Dice don Miguel de Unamuno en su conocido Del sentimiento trágico de la vida:

... estoy convencido de que resolveríamos muchas cosas si saliendo todos a la calle y poniendo a la luz nuestras penas, que acaso resultasen una pena común, nos pusiéramos en común a llorarlas y a dar gritos al cielo y a llamar a Dios. Aunque no nos oyese, que si nos oiría. Lo más santo de un templo es que es el lugar a que se va a llorar en común. Un miserere cantado en común por una muchedumbre, azotada del destino, vale tanto como una filosofía. No basta curar la peste, hay que saber llorarla. ¡Sí, hay que saber llorar! Y acaso esta es la sabiduría suprema (citado en Lutz, 2001: 313).

En nuestra cultura con frecuencia adoptamos actitudes represivas ante el llanto. A no ser que la cercanía sea excesiva, por ejemplo, al dar un pésame preferimos hacerlo en palabras, y quizá, como en el soneto de Sor Juana, el llanto acude solamente para llenar aquellos vacíos expresivos que deja el lenguaje verbal.

En otro ámbito, consideramos muy normal, por ejemplo, el acto de limpiarnos las lágrimas, y de hecho nos proveemos de un buen pañuelo (o sucedáneos) cuando sabemos de antemano que vamos a llorar; pero incluso esto, que parecería un gesto natural de cierta higiene, tampoco es igual en todas las culturas:

Una pareja misionera con la que hablé describió las dificultades que encontraron para aprender a llorar en los funerales de sus nuevos amigos tanzanios para no destacarse. La mujer lloraba en un pañuelo de papel, lo que los Makonde encontraron raro, pues se preguntaban por qué no dejar caer libremente las lágrimas. Pero más aún los desconcertó el hombre, que lloraba en un pañuelo de tela que volvía a introducir en el bolsillo. Deseaban saber por qué guardaba las excreciones de ojos y nariz. ¿Es que tenían algún significado especial? (Kottler, 1997: 117).

Las lágrimas suelen acompañar las ceremonias con que se marcan las grandes transiciones de la vida: bodas y funerales. También están presentes, en menor escala, en ceremonias religiosas co- mo primeras comuniones, bar-mitzvah, o en celebraciones como las fiestas de cumpleaños de quince o dieciséis, que señalan pasos de una época de menor madurez a una de mayor, con el consiguiente desprendimiento emocional y posibilidad de separación familiar. La emotividad natural de estos ritos puede determinar que algunas personas lloren indiscriminadamente en cualquier momento de los mismos, que lloren durante todo el ritual o que no lloren una sola vez en público y guarden sus lágrimas para un momento más privado. Pero en algunas sociedades los momentos del llanto también están señalados por hechos que estimulan la emotividad (discursos, ritos determinados -litúrgicos o profanos -...), y pueden incluso marcar una gran diferencia con aquellos momentos en los cuales no se llora.

En los velorios acartonados y prefabricados del cuento de Cortázar los parientes lloran apenas ven entrar a alguien. En la encuesta aplicada para este trabajo, 15 personas $(46,9 \%)$ aseguran llorar en los funerales cuando sienten el impulso de hacerlo, independientemente de que haya o no gente cerca. Sin embargo, si observamos algunas ceremonias fúnebres, advertiremos que los llantos y las lamentaciones arrecian en el momento en que alguien que acaba de llegar da abrazos de pésame a los deudos, así como en determinados momentos de las ceremonias religiosas del funeral. De ninguna manera se sugiere que se fuercen a llorar para fingir un dolor que no sienten; pero es en esos momentos cuando el llanto, más allá de ser un vehículo de desahogo natural, entra a formar parte de un ritual que habla de la pena de quienes han perdido a su ser querido.

Algo similar ocurre al descubrir un féretro. En ciertos contextos, parecería incluso algo de mal gusto, y si realmente fuera tan doloroso, muy poca gente se acercaría a mirar; sin embargo, algunas personas, ignorando aparentemente el dolor o la impresión que pueda causarles ver el cadáver, se acercan y dan rienda suelta a su verídica pena en un proceso que nace del interior, pero que también tiene unas claras intenciones comunicativas hacia el exterior. 


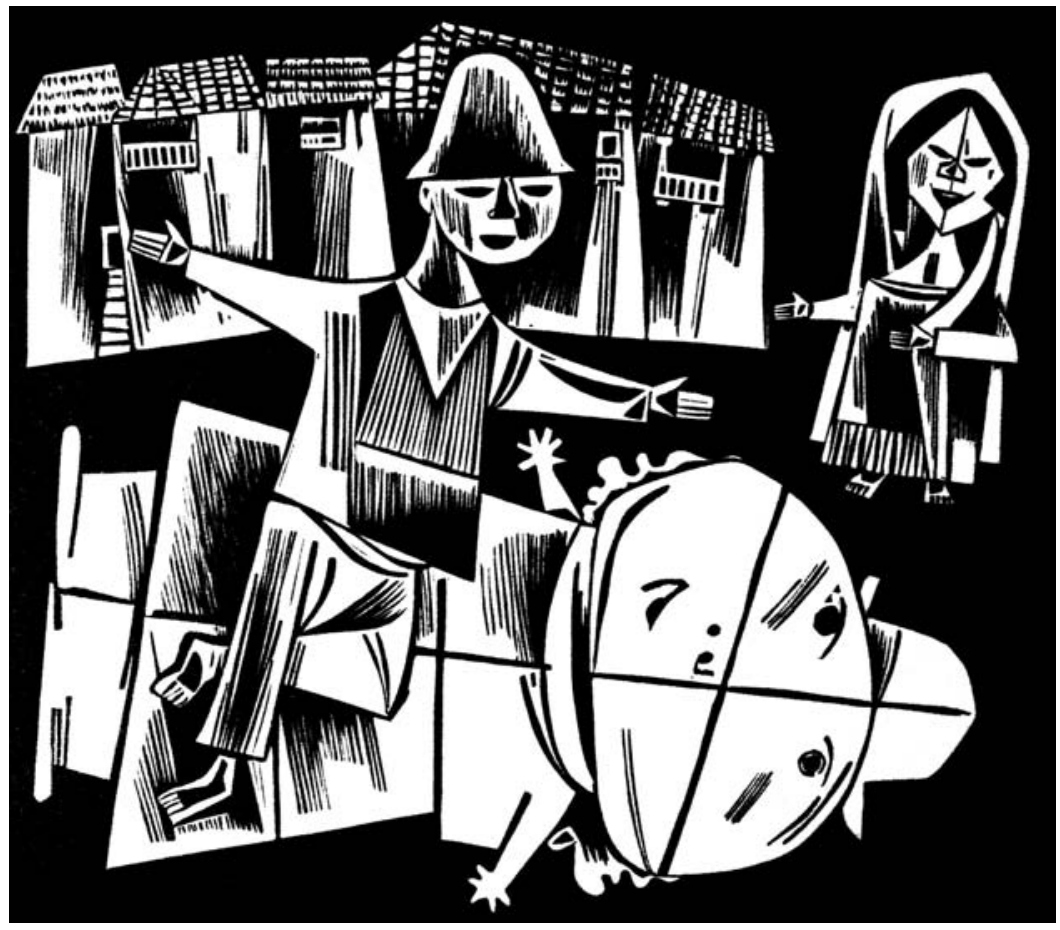

Rayuela, 1952. Serie Juegos infantiles

como un llanto en una iglesia o en un estadio.

Las lágrimas provocadas por una película u otro tipo de productos artísticos y culturales son quizá más difíciles de definir que las otras, lágrimas "reales", en medio de todo. Es posible que un ejemplo mitológico nos ayude en esta tarea: la Odisea cuenta que el rey Alcinoo, después de haber rescatado a Odiseo, organiza una cena y unos juegos en honor a su huésped, cuya verdadera identidad desconoce. El aedo encargado de amenizar la cena y los juegos interpreta una larga canción que relata las penalidades de Odiseo en su viaje de regreso a Itaca. Al escucharlo, Odiseo envuelve su cabeza en el manto que lleva puesto y llora a lágrima viva durante todo el tiempo que dura la interpretación del músico, pues se reconoce en el perso-

\section{Más allá de la simple empatía: las lágrimas en el cine}

Nuestra encuesta da cuenta de que el producto cultural que más lágrimas provoca son las películas: 25 de 32 personas $(78,13 \%, 15$ mujeres y 10 hombres) se han emocionado hasta las lágrimas con ellas. El segundo lugar lo tienen las canciones con letra y música (17 respuestas), y un tanto más alejada la música instrumental o mal llamada "clásica" (6 respuestas).

A partir de esto, pensamos que es posible que el cine haya sustituido en estos tiempos seculares las funciones del templo a las que se refería don Miguel de Unamuno. Puede constituirse en un lugar en donde las personas nos reunimos a llorar, y con frecuencia vamos con la intención expresa de hacerlo. Esta misma mañana, un amigo que atraviesa una crisis personal me decía que iba a pasarse el día viendo películas porque "quería llorar". Pero el llanto en el cine está amparado por la oscuridad y el anonimato, y eso hace que no se vuelva tan público naje de la saga y revive sus dolores, aventuras y penalidades.

En Youtube ${ }^{2}$ existe el video de una canción de Joan Manuel Serrat llamada "La primera", que cuenta la historia de un hombre que rememora cómo tuvo su primera relación sexual con una prostituta, a quien recuerda como una mujer "honrada y sincera" porque no le ofreció más de lo que podía darle, y habla también de la irremediable nostalgia de no haber tenido este encuentro con su noviecita de adolescencia. La canción es una reflexión extremadamente poética sobre las represiones no sólo políticas, sino supuestamente morales, que afectaban la vida personal y hasta sexual de la gente en tiempos del franquismo, así como sobre los anhelos y dolores masculinos relacionados con este tipo de sucesos. Hacia el final, la cámara deja de enfocar al cantante y se centra en dos asistentes al concierto. Estos hombres miran al escenario arrobados, con los ojos humedecidos y un evidente gesto de llanto a duras penas contenido. Es obvio que se sienten profundamente identi- 
ficados con las situaciones y sobre todo con las emociones de las que habla la canción.

Cuando lloramos con relatos como una película, una novela o, como en el caso anterior, con una canción, es posible que todos seamos un poco Odiseo, pues nos reconocemos en esos textos y volvemos a experimentar las duras o maravillosas sensaciones de las diversas etapas de nuestra vida.

En este sentido, tuve una experiencia similar al ver, por primera y por segunda vez, la película Recuerdos de amores pasados (Jocelyn Moorhouse, How to make an american quilt, 1995), una reflexión sobre el amor, el matrimonio y las crisis de pareja. La primera vez estaba todavía casada, aunque ya se veían venir problemas. La segunda vez llevaba varios años de separación y ya estaba divorciada. En ambas ocasiones lloré. La primera porque me trajo esperanza en medio de los problemas. La segunda porque quizá me sentí como Odiseo al escuchar de labios del aedo su propia historia, y porque me llevó a una comprensión mucho más amplia, desde una experiencia más cercana a la de los personajes, de la problemática que presenta esta película y a las fuertes emociones que se experimentan con la ruptura. En ambos casos, hubo una identificación con el relato y los personajes. Y aunque la tristeza propia de estos desencuentros no podía faltar, no diría que lloré exclusivamente porque la película fuera triste, sino porque me sentí identificada con todas las emociones y procesos que presenta.

Tal vez este sea, finalmente, el secreto de por qué nos gusta llorar en el cine. No se ha oído a casi nadie decir que una película que le haya hecho llorar haya sido mala o desagradable. Así como no se ha oído a casi nadie decir que haya llorado con una música horrible, o mirando una obra de arte mediocre. Todo lo contrario. Las lágrimas que surgen ante películas, música u obras pictóricas o escultóricas son lágrimas producidas por la emoción de habernos acercado a vislumbrar lo que de sublime y trascendente, y al mismo tiempo lo que de humano y cotidiano encierran y difunden los actos creadores del arte y la literatura. Se llora con La vida es bella porque nos conmueve profundamente la fortaleza de ánimo de aquel padre que vence al miedo y la desesperanza con su desgarrador sentido del humor. Se llora con Perfume de mujer porque reivindica la justicia y la integridad. Se llora al ver Despertares porque en medio de la fatalidad nos enseña el camino para ser más humanos y solidarios. Se llora al leer o mirar en el cine Las noches blancas porque sentimos la fugacidad de las ilusiones y la crueldad de la esperanza que por un momento nos hizo desear lo que desde siempre supimos imposible.

\section{¿Llorar o no llorar?}

¿Será esa la pregunta?

Estas líneas están escritas por alguien a quien durante mucho tiempo le resultó difícil expresarse con lágrimas; por ese motivo, en un medio latino y andino, sufrió cierto tipo de velada censura moral y tuvo que escuchar frases irónicas como: "ella es valiente (imagínense el tonito)" porque, para mayor escarnio, es una mujer, y así como se dice por ahí que los hombres no lloran, mujer que no llora... ya se sabe. Después, como escritora de ficción, he hecho llorar a muchísimos personajes, mujeres y hombres, y quizás a través de ellos he aprendido a llorar las lágrimas que por cierta disposición y modo de ser me habían sido negadas en determinadas etapas de mi existencia.

Por otro lado, y como todo en la vida, las lágrimas tienen ciertas aristas: su uso para la manipulación, que aprendemos desde la más tierna infancia, o la valoración y desvalorización social de acuerdo a los esquemas que nos vamos imponiendo casi imperceptiblemente, y que con más ligereza que razón nos permitimos emitir en forma de juicios, a partir de nuestros propios temores y condicionamientos, sobre la gente que llora o que no llora.

Ha habido épocas y situaciones que han pretendido negarles un lugar a las lágrimas (pensemos en la Revolución Industrial), pero 
entonces el arte y la literatura, llámese Dickens, Dostoyevski o cualquier otro, las han rescatado del abandono y el olvido; ha habido otras épocas que habrían podido naufragar en ellas (imaginemos a los veinte mil soldados de Roland llorando en los funerales de su líder hasta caer desmayados de las monturas, o recordemos la voz poética de Bécquer que, en medio de su inmenso sufrimiento, se alegra porque aún le quedan lágrimas), pero estos mismos héroes han puesto su contraparte de entereza y serenidad en otras situaciones; sin embargo, como seres individuales y como comunidades, las lágrimas por sí solas ocupan su lugar en nuestras simples historias personales y en la historia de la humanidad, y por supuesto, también ocupan un lugar importante las construcciones simbólicas y sociales que marcan el contexto de las expresiones emotivas.

En lugar de ¿llorar o no llorar?, podríamos plantearnos mejor esta pregunta: ¿cómo entender y cómo acercarnos a nuestras lágrimas y a las de los demás? Tal vez algo básico sea valorarlas como lo que realmente son: un fenómeno mucho más complejo que una secreción ocular producida por el estrés, las emociones o incluso el deseo de llamar la atención o manipular. El llanto es una expresión humana que trasciende el ámbito de lo personal y puede leerse también, más allá de lo psicológico, desde lo social y lo cultural. Las lágrimas, desde su presencia o su a veces desconcertante ausencia, hablan por sí solas cuando las palabras pierden fuerza o valor: asustan, incomodan, manipulan, es cierto; en ocasiones los llantos por los héroes o los líderes desaparecidos en acciones o combate pueden llamar a la venganza o la violencia (esa es la base de la prohibición de los funerales de Polínices en Antígona, por parte de Creonte, por ejemplo); pero también comunican, integran, propagan el afecto y la empatía. Dicen de los valores y de los temores de las familias, las épocas, los pueblos y las culturas.

En el Apocalipsis se menciona que algún día Dios "enjugará todas las lágrimas de nuestros ojos". Para qué, podríamos preguntarnos con un poco de sorna: ¿No incluyó en el equipo el mismo Dios el aparato lacrimal? ¿ No cuenta la misma Biblia reencuentros y abrazos inundados de llanto de ternura y alegría como los de David y Jonatan o José y sus hermanos? ¿No conocerá Dios esa delicia que es, cuando alguna penita traicionera nos ataca, abrazarse a una almohada o a un peluche, $y$ llorar a discreción mientras suena en la guitarra un Preludio llamado Dolor del padre Donostia? Y por algo esos textos están escritos mucho antes de que se inventara el cine, y así se pudiera disfrutar el indudable placer de llorar a gusto mientras nos regodeamos con Despertares, Perfume de mujer, La strada o Cinema Paradiso.

Aunque muchos relatos mitológicos hablan de un llanto sin fin, sobre todo si se trata de la pérdida de un amante o de un hijo, dice el poeta alemán Heinrich Heine: "Por muchas lágrimas que uno derrame, siempre termina por sonarse la nariz" (Lutz, 2001: 362). Y así es. Pero el período comprendido entre el inicio del llanto y el hecho de sonarse la nariz es quizá uno de los escasos momentos que la época actual nos proporciona para volvernos hacia dentro y poder observar, más allá de la prisa y el tráfago de cada día, no solamente el sentido individual de nuestros sentimientos, sino toda la carga humana y ancestral que traen las lágrimas a nosotros, que nos lleva hacia ellas, y que así le da significado a nuestra vida emocional, tanto como personas cuanto como sociedades, y posiblemente también como una humanidad que no ha perdido aún su capacidad de sentir, y de saber decirlo con el poético y misterioso lenguaje del llanto. 


\section{Bibliografía}

- BÉCQUeR, Gustavo Adolfo: Leyendas y rimas, Barcelona, Aula de Literatura. Vincens Vives, 2002.

Rimas y leyendas, Bilbao, Editorial Vasco Americana, 1968.

- BORGES, Jorge Luis, Narraciones, Bogotá, Editorial La Oveja Negra, 1983.

- CORTÁZAR, Julio: Historia de cronopios y de famas, Buenos Aires, Editorial Sudamericana, vigésima cuarta edición, 1991, pp. 52 - 57.

- HOMERO, Odisea...

- KOTTLER, Jeffrey A: El Lenguaje de las Lágrimas, trad. de Marco Aurelio Galmarini, Buenos Aires, Paidós, 1997.

- LUTZ, Tom: El llanto. Historia cultural de las lágrimas, trad. de Eunice Cortez Gutiérrez, Madrid, Taurus, 2001.
- RISO, Walter: De regreso a casa, Bogotá, grupo editorial Norma, 1997.

- UNAMUNO, Miguel de: Del sentimiento trágico de la vida, Buenos Aires, Cía. Argentina de Editores, 1962.

\section{Portales de Internet}

- http://buscon.rae.es/draeI// (Diccionario de la Real Academia de la Lengua)

- http://members.tripod.com/Heron5/sor1.htm (Poema de Sor Juana Inés de la Cruz)

- http://www.btk.elte.hu/palimpszeszt/pali08/ 28.htm\#I donde se encuentra el estudio de MENCZEL, Gabriela, El llanto en los cuentos de Julio Cortázar.

- http://www.youtube.com/watch?v=HIoQHJKrAwc (para ver el video de Serrat)

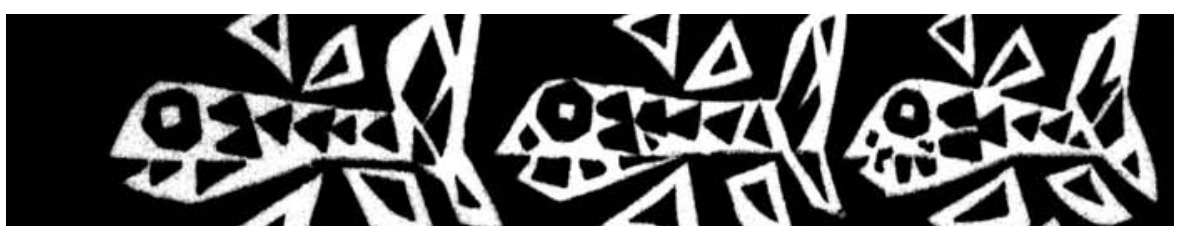

Ritual del río, 1983. Fragmento

2 Alfred Stern, Filosofía de la risa y el llanto, Buenos Aires, editorial Imán, s. d., citado en el estudio de Gabriela Menczel, El llanto en los cuentos de Julio Cortázar, en http://www.btk.elte.hu/palimpszeszt/pali08/28.htm\#J

3 http://www.youtube.com/watch?v=HIoQHJKrAwc 